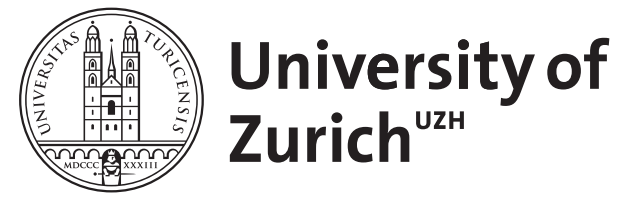

Zurich Open Repository and Archive

University of Zurich

University Library

Strickhofstrasse 39

CH-8057 Zurich

www.zora.uzh.ch

Year: 2011

\title{
Emerging themes in Economic Geography: Outcomes of the Economic Geography 2010 workshop
}

\author{
Aoyama, Y ; Berndt, Christian ; Glückler, J ; Leslie, D
}

DOI: https://doi.org/10.1111/j.1944-8287.2011.01114.x

Posted at the Zurich Open Repository and Archive, University of Zurich ZORA URL: https://doi.org/10.5167/uzh-50472

Journal Article

Published Version

Originally published at:

Aoyama, Y; Berndt, Christian; Glückler, J; Leslie, D (2011). Emerging themes in Economic Geography: Outcomes of the Economic Geography 2010 workshop. Economic Geography, 87(2):111-126.

DOI: https://doi.org/10.1111/j.1944-8287.2011.01114.x 


\title{
EDITORIAL
}

\section{Emerging Themes in Economic Geography: Outcomes of the Economic Geography 2010 Workshop}

\author{
Participants in the Economic Geography 2010 Workshop $^{1}$
}

\section{Background $^{2}$}

Economic Geography sponsored a workshop to brainstorm collectively the emerging research themes in economic geography. We gathered a small group of midcareer scholars from 19 institutions in 7 countries on April 12-13, 2010, in Washington, D.C., to address what we considered a collective concern: that our discipline could use a significant boost in theoretical and thematic developments at this particular juncture. The workshop was intended to be one of the journal's many contributions to disciplinary activities and ongoing efforts to keep the discipline vibrant for the next generation. The workshop aimed to achieve multiple goals. First, this was an attempt to develop a sense of collective responsibility for the discipline's future. Economic geography is no longer monological and singularly centered, as Peck and Olds (2007) observed in their assessment of the Summer Institute of Economic Geography. Indeed, prior to the workshop, quite a few participants reported that they did not have a particular identity affiliation to the discipline but instead enjoyed multiple disciplinary affiliations through joint appointments or appointments in multidisciplinary departments. The increasingly specialized and fragmented nature of the discipline and the resulting "disappearing of the middle" translate into fewer scholars who are dedicated to the discipline, which, in turn, endangers the survival of the discipline. As Johnston $(2002,425)$ stated, "eternal vigilance is necessary to survival" of a discipline, and mobilization, as in the language of Latour, is a first step in disciplinary change (Johnston 2006). Thus, as editors with a disciplinary name that crowns the journal, we thought that the time was ripe for a deliberate intellectual mobilization.

Second, there is a unique generational dimension of the aforementioned disappearingof-the-middle problem. Midcareer scholars today bear the burden of disciplinary leadership while being subject to significantly heavier administrative loads than their predecessors. In addition, although we knew each other's work well, we did not know each other socially since most of our early careers predated the start of the Summer Institute. This workshop was envisioned as an opportunity to move beyond our daily chores by carving out a thinking space to generate broader cross-cutting reflections on the future of our discipline. Finally, we were aware that individual benefits must accompany efforts to shape the discipline's future. We designed this workshop as a venue in which scholars could sharpen their own ideas through intensive interactions and develop a collaborative research agenda.

\footnotetext{
1 The participants included Chris Benner, Christian Berndt, Neil Coe, Ewald Engelen, Jürgen Essletzbichler, Jim Glassman, Johannes Glückler, Michael Grote, Andrew Jones, Robin Leichenko, Deborah Leslie, Peter Lindner, Mark Lorenzen, Becky Mansfield, James T. Murphy, Jane Pollard, Dominic Power, Eric Stam, Dariusz Wòjcik, and Matthew Zook. In keeping with a small workshop format, we could not invite everyone on our list, and some of the invited were unable to attend due to schedule conflicts. Yuko Aoyama served as an organizer of this event and Gernot Grabher, David Rigby, and Henry Wai-Chung Yeung participated as observers and offered various substantive inputs during and after the workshop.

2 Yuko Aoyama
} 


\section{Acknowledgment}

\author{
Yuko Aoyama expresses her \\ sincere thanks to all the \\ participants for their \\ patience and willingness to \\ come along with this \\ "experiment" and to spend \\ time talking and writing. She \\ also thanks the editors for \\ their input, guidance, and \\ support. Last but not least, \\ she especially thanks Joanne \\ Miller, former managing \\ editor of Economic Geography, \\ and Rory Horner, a Ph.D. \\ candidate at Clark University, \\ for their help in organizing \\ the logistics of the \\ workshop.
}

Research has shown that collaborative scholarship produces high-impact work that once was the domain of single authors, and this tendency increasingly applies to the social sciences as well (Wuchty, Jones and Uzzi, 2007).

Prior to the workshop, each participant was asked to provide two ideas that have the potential of serving as key concepts in the future of our discipline, to be ready to justify and defend them, and to convince others as necessary in a small-group setting. The participants were encouraged to keep in mind two additional criteria as they conceived ideas: policy relevance and interdisciplinary cache. While not a new concern (see, e.g., Martin 2001), policy relevance remains crucial for the survival of a discipline, especially given that competing and closely associated disciplines (such as geographic economics) have been far more successful in engaging with policy circles. Policy relevance also requires active engagement to empirical realities so as to avoid "another missed boat" (Dicken 2004). Interdisciplinary cache is equally crucial; crossdisciplinary recognitions strengthen the discipline, expanding the disciplinary boundaries by enrolling top-quality students and a greater number of future scholars, which translate into greater leverage in soliciting additional faculty positions. As Thrift $(2002,295)$ commented, "a modern discipline becomes good by constantly exposing itself to competition from the best across the sciences or social sciences or humanities." In sum, policy relevance does not rule out intellectually exciting ideas that would make theoretical advances, and we should aspire to be an exporter of ideas while maintaining an openness to imports from other disciplines.

Finally, this was truly a collective endeavor. All the participants shared their thoughts and contributed to writing this editorial. Some served as session leaders at the workshops, and others led in writing their sections. Notwithstanding differences among us, we decided to have a collective name to our credit. Scholars who contributed to each theme presented here have been identified alphabetically, with an asterisk denoting the group organizer. The names of some scholars appear more than once because they volunteered to participate in more than one group.

\section{Five Research Themes}

We sought to achieve our goals by maintaining both breadth and specificity in the workshop discussions. 
We did not propose a particular set of themes in advance of the workshop. Instead, to generate multiple discussions as a way to articulate research themes that may contribute to the future of our discipline, we opted for an experiment. The first day was spent in five small, break-out sessions in the morning, which were repeated with different group members in the afternoon. These small groups were used as a focusing device to unpack specific concepts that were proposed by individual members and to identify broader, cross-cutting issues. Some themes that were proposed at the beginning of the workshop included resilience, finance, nongrowth, governance, methodological innovation, and reconceptualization of key concepts, such as economy, property, and markets. On the second day, we let themes and research questions emerge organically and autonomously.

The groups were then largely left to their own devices to generate their contributions, which ultimately led to the following five themes: (1) networks, firms, and markets; (2) global environmental change; (3) geography of finance; (4) digital property; and (5) a more "global" economic geography. Since we necessarily depended on the often-narrow and specialized expertise of each participant, these emerging themes are not intended to represent exclusively our discipline's future. Instead, these themes (some of them recurring, others new) are identified as worthy common grounds to further our individual scholarship, which may, in turn, result in potential research directions. It should also be noted that these sections reflect different approaches taken by each group, including disagreements and variation in perspectives within a group.

\section{Networks, Firms, and Markets ${ }^{3}$}

Over the past two decades, there has been growing interest in understanding economies through the lens of networks. Rather than privileging individuals, firms, or industrial sectors as units of analysis, economic geographers have examined the variety of actors in networks, their ongoing relations with other actors, and the ways in which they exercise power. The development of relational theory, as well as network methodologies in sociology and organization studies, has inspired much of this work (Grabher 2006).

Economic geographers have approached networks from two main vantage points. In the first conception, networks are used to describe a particular form of governance. The neoinstitutionalist debate, for example, led economic geography into a reduction of the notion of networks to trust-based forms of interfirm cooperation. There is growing recognition, however, that networks need not be cooperative and friendly but can be the fruit of rivalry and competition, that relations are not only about linkages but also about the absence of linkages (structural holes). In addition, there is growing recognition that networks are not just a mode of governance but also a way of thinking about social exchange. In this second conceptualization, networks are seen as a metaphor-or as an analytic tool-with which to understand the characteristics of social relationships.

Recent approaches have also witnessed a convergence in "relational thinking" and different streams of theory, such as actor network theory, network analysis, and field theory. A shared belief in these approaches is in the "anticategorical imperative" (Emirbayer 1997). This imperative argues against a substantialist conception of social phenomena as categories or objects. In contrast, social phenomena are seen as fluid and interdependent and mutually constitutive.

Also emphasized are the meanings, ambiguities, and contextualities that are communicated within networks (Pachucki and Breiger 2010), which allow for networks to evolve

\footnotetext{
Christian Berndt, Johannes Glückler,* Deborah Leslie.
} 
in the first place. It is in this context that a dialogue among proponents of relational theory, cultural theory, and the performativity literature may be particularly fruitful. The latter literature starts with an assumption that economic entities, such as the firm or the market, are not pregiven but are understood as constantly in the making. Seen in this light, economic networks are a performative act; their outcomes are labored, uncertain, and often contested. The success of a network depends on the ability of some actors to enroll other actors, objects, technologies, and procedures. Accordingly, economic entities turn into arrangements of people, things, and sociotechnical devices that format and frame products, prices, competition, places of exchange, and mechanisms of control. Relational and performative thinking have become overarching perspectives in social theory that shift the analytical focus from attributes and categories to practice, process, and emergence. In the next section, we highlight the value of such an approach for understanding two aspects of the economy: firms and markets. Integrating insights from both relational and performative approaches, we would like to stimulate a deeper interest in understanding firms and markets as networks and in exploring the "making of" of these two entities.

114 Firms. Ever since the early invitation for a geography of enterprise in the 1960s, interfirm processes - be they local clusters or global production networks and commodity chains - have continued to prevail over intrafirm relations. Yet how are we to understand the geographies of innovation, knowledge transfer, and production organization if we exclude a large part of economic reality from our analyses? In this respect, economic geography could engage more systematically with the new organization theory. It is exciting to see how important geography has become in organization science, which appreciates the social and geographic contextuality of organizing. Organizations experience ever more complex geographies and struggle with problems related to ever-more-complex spatial and temporal divisions of labor. In an economic context in which diversity, versatility, and flexibility are key organizational challenges, and the boundaries between firms and markets have become increasingly blurred, the "integrated firm" is turning into the "network firm."

Yet a detailed understanding of organizations as networks and a focus on the diversity of organizational forms may not go far enough, given their emphasis on the stabilization of specific organizational ecologies in institutional contexts of uncertainty and volatility. Critics have argued that it is the "heterarchical organization of diversity," not the "diversity of organization," that is at stake (Stark 2009). In rapidly changing constellations, the challenge for individual and collective actors is not how to produce stability but, rather, how to (re)create the possibility for dissonance, disjuncture, and difference and to exploit the frictions that result from their interplay. Such an understanding completes the shift from the firm as a category to firms as bundles of practices and material arrangements.

Markets. It is striking that the market has been largely treated as a black box-not only in economic geography and so-called heterodox approaches but also within mainstream economics. This is even more astonishing in the face of almost four decades of market-based economic and social policies. The main reason for this neglect may be that we believe we know everything about the market. But as recent discussions in the wake of the current financial and economic crisis have painfully illustrated, this is not the case. How exactly, then, are markets put to work? Rather than take markets for granted, such a project would focus on processes of market making (i.e., marketization) (Caliskan and Callon 2010). We call for intensified efforts to understand how real (as opposed to ideal) markets are produced, stabilized, and dissolved. The heterogeneity of contributions notwithstanding, there are three overarching matters of concern that may characterize such a project: 
Variegated markets. We argue for a more nuanced treatment of markets and marketization processes. Since economic sociologists rediscovered the market in the early 1980s, heterodox scholars in economic geography and beyond have focused primarily on product markets. However, there are a variety of markets that do not always follow the same logic (Knorr Cetina 2006). Labor markets and financial markets are obvious examples. The latter, for instance, constitute a distinct sphere of economic transactions in which accumulation and profits depend on fluidity and mobility to an extent that it is warranted to speak of the liquefaction of property rights (e.g., securitization). In the circular logic of financial markets, the referent of money is the promise of more money to come. The speculative gamelike transactions that transfer risks unremittingly to the future have little to do with the idea of self-correcting product markets following a logic of balance and equilibrium.

Moral markets. There is a need to remember the simple fact that governance in the capitalist market economy is not synonymous with "market governance." Rather, economic and social worlds are always made up of a plurality of modes of coordination. Inspired by the renewed interest in the French Convention School (Boltanski and Thévenot 2006), we insist that economic actors have the competence to refer recursively to "orders of worth," making judgments about the "quality" of a person or an object and practically structuring the coordination of economic and social processes. If one accepts that modern economies consist of multiple principles of evaluation, only one (though admittedly crucial) of which is "market rationality," one should avoid the uncritical mobilization of concepts like "the market" or "the firm."

Markets as boundary projects. Conventional economic theory still maintains a strict separation between the sphere of the market and that which lies beyond. Using this distinction to separate an abstract perfect market from concrete imperfect markets, it allows market apologists to blame unwelcome external infringements (social, cultural, political, and the like) for "market failure." Notwithstanding their sheer force, we begin with an assumption that these ordering processes are always precarious and incomplete. This assumption gives rise to ambivalent and contested border zones, borderlands of "exclusion inclusion" (Mitchell 2007), where struggles are waged about who and what are included in the realm of the market and who and what are not. Such an understanding of the contested nature of marketization processes could usefully connect with work that stresses how difference and inequality are integral parts of the formation of economic entities, rather than things to be added on, external to the economy, and part of a different sphere alternatively called "society" or "culture."

In sum, we call for an economic geography that understands that networks, firms, and markets are actively made of practices and processes, involving particular forms and techniques of calculation, as well as distinctions and exclusions. Such an approach breaks down the boundaries between the social and the economic and the cultural and the material. As Mitchell $(2002,301)$ argued, "the economy is an artifactual body-a fabrication yes but as solid as other fabricated objects, and as incomplete."

\section{Economic Geography of Global Environmental Change: Understanding and Creating New Socionatural Futures ${ }^{4}$}

Global environmental change presents a new set of empirical, conceptual, and normative challenges and opportunities for economic geographers. It can be defined broadly to include a range of ecological, geophysical, and biochemical changes across multiple scales,

${ }^{4}$ Jürgen Essletzbichler, Robin Leichenko, Becky Mansfield,* James T. Murphy, Erik Stam. 
such as the changing global climate, the proliferation of "anthropogenic biomes," and the human body remade by environmental contaminants (e.g., Ellis and Ramankutty 2008; Leichenko and O'Brien 2008; M. Murphy, 2008). As such, global environmental change is not something that humans do to nature but rather refers to 21 st-century postindustrial "socionatures" that emerge from the intersection (or "coupling") of numerous social and natural processes (Castree and Braun 2001; Turner, Lambin, and Reenberg 2007). While these socionatures are not exclusively economic, they are fundamentally economic; economic practices are central drivers of environmental change, and, at the same time, environmental change creates diverse economic challenges and opportunities. Furthermore, because these environment-economy interactions are inherently spatial and multiscalar, economic geographers have much to contribute to and learn from analyses of them.

Environmental economic geography is emerging as a significant and vibrant subfield to address questions about the socioeconomic, political, and technological drivers and implications of environmental change (Gibbs 2006; Bridge 2008; Hayter 2008; Bumpus and Liverman 2008; Soyez and Schulz 2008). Emerging scholarship combines longestablished expertise in such areas as globalization, markets, firms, innovation, and

116 regional development with new theoretical advancements in environment-economy relationships. We believe that a focus on socionature offers a promising path forward with respect to a number of pressing questions. How do economic processes, including the construction of the built environment, contribute to environmental changes? How do environmental changes present new economic challenges, such as short- and long-term disruptions caused by extreme climatic events (Alley et al. 2005; Nordhaus 2006, 2010)? What types of technological, institutional, and financial innovations are emerging as the result of efforts to address global environmental change, such as emission markets (Knox-Hayes 2009), new ways of governing common pool resources (Ostrom 2009), or financial instruments to hedge environmental risk, and what are the socioeconomic and environmental outcomes of these innovations? How are changing socionatural conditions affecting regional economies and labor markets, and what types of responses and developmental strategies are being pursued? Such questions open up new veins of research in economic geography and bring unique insights from economic geography to multidisciplinary efforts to understand socionatures.

However, such questions represent neither the full possibility nor the full responsibility of economic-environmental scholarship. A new direction is for economic geographers to examine how socionatures challenge fundamental economic concepts, such as growth, value, worth, sustainability, equality, and efficiency. Doing so also raises important and unavoidable normative questions that economic geographers should make explicit. Why does recognizing and studying socionatures create these new possibilities and responsibilities for economic geographers? First, the focus shifts: economic relations do not lead to "destruction," "protection," or "restoration" of nature per se; instead, economic and environmental processes intersect to produce new socionatures, which then reshape possibilities for future economic and environmental relations. Crucially, this perspective then removes a common justification for the way things are and in so doing calls into question assumptions about what "just is." That is, once there is no external nature - something unsullied by human activity - we cannot treat anything as "just natural, just the way things are." This perspective also calls into question our basic concepts and raises normative questions: we can no longer evaluate economicenvironmental processes and outcomes on the basis of how "natural" they are. Instead, particular socionatures (and the various processes from which they emerge) need to be evaluated on the basis of their effects on people and environments. In addition, once "good" socionatures are no longer determined by how natural they are but emerge from 
socioenvironmental interactions, power relations among actors at multiple scales must be made explicit. This is the normative and inherently political responsibility that comes with recognizing socionatures. At the same time, insights from economic geography on the spatial characteristics and dynamics of economic processes are essential for generating new understandings of these concepts and thus can sharpen our contribution to scholarship on 21 st-century socionatures.

"Growth" is an excellent example. Long a fundamental concept in economic geography and in economic thought and practice more broadly, we can no longer assume that growth is good, or even that we know what growth is. Instead, this becomes a research question and calls for new efforts to create and use other measures of economic performance and social progress (Costanza et al. 1997; Stiglitz, Seng, and Fitoussi 2009). An important implication is that growth-oriented policies are not purely technical or objective but are inherently normative and political, which then suggests that growth should be decentered as a central goal of economic (and economic-environmental) activity. Rather than assume growth is a goal, it is crucial to address analytical-normative questions about the ways in which particular economic-environmental relations are positive or negative. Economic geographers can contribute significantly to debates on possible futures by studying the myriad spatial dynamics and geographically uneven outcomes of contemporary socionatures.

Questioning a concept, such as growth, does not imply the promotion of a nongrowth economy as better for human and nonhuman organisms or environments. Rather, the point is that no particular goal or orientation can be presumed to be good by virtue of its naturalness or some inherent quality. What are good socionatures and the economicenvironmental relations necessary to sustain them will be determined by making hard and politically fraught decisions about who and what will benefit, how, where, and on what time scale. What is desperately needed, then, is for economic geographers to use and develop their expertise to answer these analytical-normative questions about unevenness and the production of socionatures and, in so doing, contribute to envisioning what alternative economic-environmental relations may be like.

\section{It Is the Geography of Finance, Stupid!}

There is an urgent need and a unique chance to push the agenda of a geographic take on finance. The global capitalist system is undergoing a transition comparable to the great transformations of the 1930s and the 1970s. The global financial crisis of 2007-9 has discredited the dominant explanations of finance and its relationship with economic development established by mainstream financial economics. The rise of emerging markets and sovereign wealth funds (SWFs), accompanied by the eroding legitimacy of Americanstyle capitalism, is reshaping the map of financial flows and power. At the same time, growing environmental concerns provide an invitation to construct new markets, as well as new metrics to evaluate economic performance in a more inclusive manner. Whether these transformations result only in the rise of new centers and spaces of accumulation or will initiate a genuine shift toward more equitable, stable, and sustainable varieties of capitalism remains to be seen. But whatever their effects, it is obvious that the field of finance will become one of the main geopolitical and geoeconomical battlefields of the near future.

How can economic geographers make a difference in the study of finance? We have at least three strengths to build on. First, we have expertise using multimethod approaches, ranging from interviews with policymakers and ordinary users of financial services to

\footnotetext{
${ }^{5}$ Ewald Engelen, Michael Grote, Andrew Jones, Jane Pollard, Dariusz Wójcik.*
} 
systematic mapping of the global circuits of money. Second, economic geographers have a tradition of conducting carefully crafted comparative case studies of places and sectors. Third, we strive for a holistic understanding of finance, one that incorporates economic, social, political, environmental, and cultural issues, which gives us a natural openness both to the other social sciences and to new empirical developments. Given that economic geographers of finance are few (albeit growing in number), interdisciplinarity is both an opportunity and a necessity. We can join forces not only with social studies of finance and studies of financialization but also with financial economists, many of whom are now willing to sacrifice the canon and models for the sake of relevance and empirically grounded work.

Which concepts does a geography of finance have to offer? Here, the notion of circuits of capital, with the drive for profit making at their center, remains a promising and inherently geographic framework. The concepts of agglomeration, clusters, and networks are attractive descriptors of specific configurations on the map of the world economy, but does not making money make the world go round? The new economic geography (NEG) can now claim a Nobel Prize for economics and fills the pages of the World Development

118 Report, but its models focus on tangible goods and transportation costs, which disables their contribution to an in-depth analysis of finance. For example, what can NEG say about carbon markets, economic crises, or the spatial consequences of failed financial products? Moreover, NEG relies on a conceptualization of homo economicus, which is now in retreat. Thus we argue for the potential power of the concept of interconnected circuits of capital as grounded, ambitious, and open to economic as well as political, social, and environmental analysis.

The challenge, however, is to disentangle the concept of circuits of capital from its Marxian heritage. Fundamental to our agenda is recognition of the spatiality of the circuits of capital. Economic geography has to consider questions about the uneven development of capitalism along with those concerning its evolving forms of institutional and territorialized differentiation. Such a framework affords more autonomy to state, space, individuals, and nature (not just as accomplices or products of the capitalist circuit) and takes seriously the catastrophic experience of communist countries. We also need to revisit questions about the extent to which contemporary financialized capitalisms have systemic properties and are not the outcomes of historical mistakes and accidents.

To make the concept of circuits of capital relevant to policy, it is crucial to map and document them empirically for different types of capital, in different places, and at different scales. The financial crisis of 2007-9 has generated many spatial issues that cry out for explanation. How did so many supposedly rational actors overlook the risks involved in financial products? Where did - in a physical and institutional sense - the information about the risks get lost? In what ways are different states, firms, households, investors, and consumers connected to circuits of capitals, resulting in different trajectories of involvement in the crisis and financialization in general? Questions such as these suggest that spatiality is not only the backdrop against which geofinancial developments play themselves out but also is a causal variable that could well be key for solving some of the problems facing the world.

The spatiality of circuits of capital should be considered as a gateway into the complexities of information management. Global city theory, for instance, can be recast as a mode of information management through circuits of capital by salaried professionals, including investment bankers. Insights from other social sciences can be integrated. The presence of imperfect information, for example, highlights the role of proximity, explaining the fragmentation of the spatial circuits of capital. Combined with new models of agency that are being developed by behavioral economists and pragmatist sociologists, 
imperfect information could explain why circuits are prone to breakdowns when they are extended over time and space. We need to augment our grasp of information brokered through the pricing system of financial markets. As demonstrated by the crisis, financial markets are not just about the allocation of capital, as radical political economy would like to have it, but about pricing and access to information through spatial circuits. Framing it in this fashion allows for an interdisciplinary intercourse among the economic and social sciences of finance. Economic geographers, by insisting on the spatial nature of information, have an opportunity to initiate innovations through such a dialogue.

To summarize, the geography of contemporary economies cannot be understood without understanding finance, for finance has simply become too important, and finance cannot be understood without attention to its intrinsic spatiality. Although economic geographers have regretted missing boats in the past, the challenge now is to claim a central role in the evolving debate on the shape of global capitalism. There is no time to lose.

\section{Digital Property: Challenges, Processes, Regulation ${ }^{6}$}

It is surprising that economic geography's engagement with digital spaces and processes has to date been largely ghettoized to a subfield rather than a central theoretical and empirical focus of the wider discipline. As digital technology becomes nearly ubiquitous, we call on economic geography to develop an active and critical engagement with the economics of digital transitions.

A coherent disciplinary agenda could usefully start with the issue of property. The digitalization of everything from business to social networks centrally involves the creation, distribution, and exchange of digital property, which fundamentally challenges traditional notions of property. Unlike other types of property - whether land, machinery, money, or intellectual - digital property need not be bounded by either physical constraints (e.g., a specific plot of land can accommodate only one building) or exclusivity (e.g., there can be only one title to a certain pot of money). Instead, digital property can be copied, moved, and used with little marginal cost or effort. Although regulatory and legal frameworks set constraints on the flows of digital property (e.g., onetime use, protecting specific layers within digital property, preventing simultaneous "possession"), these are constructs that do not alter the essential nature of digital property. Focusing on property means focusing on the evolution of the core foundations of contemporary economic systems: possession (control over a resource) and title (the expectation that rights to control a resource will be recognized). The digitization of property is leading key economic actors, including corporations and nation-states, to pursue new strategies in their attempts to exercise and enforce these fundamental property rights. To exercise possession, these strategies must often focus less on limiting physical access to others and more on regulatory, legal, and intimidatory methods, along with efforts to differentiate themselves from and outpace potential rival users of the property in economic markets. Title rights, while deeply entrenched in national legal structures, also need to be negotiated in complex bilateral and multilateral international processes, raising important questions about the impact of geographic variations in these enforcement mechanisms.

Digitization has two significant effects vis-à-vis property: (1) new ways to use old types of property and (2) new types of property built from digital foundations. In many industries digitization entails the transition from the exchange of material property to the exchange of digital property; in the music industry, for example, the buying and selling of

\footnotetext{
${ }^{6}$ Chris Benner, Ewald Engelen, Dominic Power,* Matthew Zook.
} 
large volumes of plastic is increasingly a marginal activity. Such transitions entail structural transformations and spell the death knell to various manufacturing, distribution, and retail activities. Equally, digitization opens up for new entrants and radical realignments of hierarchies and power: witness how Google has become a major player in the global advertising industry or how iTunes and Amazon dominate many content markets. These difficulties are not merely a matter of form, but are also due to the fact that the relative velocity and flexibility of digital artifacts and processes are distinctive, for example, the effect of digitization on the mobility and velocity of finance markets and the growth in synthetic financial products. Ironically, the speed and ease with which digital property can move has led to the parallel introduction of "stickiness," through encryption or lawsuits, by some property owners in an attempt to retain control. Moreover, ICT's openness and ubiquity means that innovation need (or can) no longer be hoarded in the corporate structures, property structures, and intellectual property regimes of the analogue era.

The second effect on property is even more profound because it represents the creation of new types of property. For example, new markets have emerged around the coded assets

120 and liabilities of virtual spaces and worlds, such as the online game Second Life. Since these simulated environments are based solely in computer servers and their users' imaginations, the property they offer for sale (ranging from private islands to consumer goods) is completely digital and is difficult to fit into existing regulatory frameworks. Nevertheless, the active exchange of digital property is ongoing (albeit under the complete monopoly control of the operators of these synthetic worlds) and comes complete with exchange rates that allow people to purchase virtual-world currencies for offline dollars.

Another type of new property is based on the digital technologies that make recording, storing, and cross-referencing data about daily online and offline activity relatively simple and cheap. The ease in replicating data not only affects existing processes (such as marketing or customer relations) but also gives rise to new markets, actors, and industries. The digitization of everyday life is not simply about the data of offline activities moving online. It is equally about the online moving offline. Increasingly, a plethora of digital overlays (such as location-based searches via mobile devices) are structuring and appropriating material and offline property. Digital augmentation means that knowledge and navigation around the world are given digital as well as physical form. Digital augmentation and layering of our landscape (and how we find our way through it) involves processes of marking, valuing, classifying, and appropriating existing assets and raises interesting issues of control over and the status of the digital layer. How do the property rights of an augmented reality (digital graffiti or advertising overlaid on a building) intersect with existing property rights?

The developments just highlighted argue for a reconceptualization of the space economy so that the virtual is accorded the attention it demands. The speed at which digital property can free itself from territorial space severely tests regulatory regimes and therein existing business, industrial, and innovation systems. In digitally mediated processes, it is property (unbounded by the constraints of physicality or exclusivity), rather than productive factors, that is increasingly footloose. Productive factors tend to be strongly embedded in high-tech knowledge regimes to access specialized inputs (including labor) or peripheralized to low-cost regimes because of price competition. These factors certainly have geographies but are subordinate to the bewildering dynamism of the ever-changing possession and title of digitally mediated property. This is why we argue that property is a good starting point for an economic geography that is interested in engaging with how digital transitions rewire economic networks and lines of power and how new spatial divisions of labor and exchange will change our world. 


\section{Towards a More "Global” Economic Geography”}

Our contribution focuses squarely on the need to think critically about the geographies of economic geography-in terms of both our topics of study and the knowledges and theoretical frameworks that we (re)produce. It has become something of a truism to state that today's global economy is more interconnected than that of previous eras. Rapid global shifts in both production and consumption have exploded old dichotomies of core periphery and North-South, creating a world economy that is highly dynamic and increasingly polycentric. Intense transnational economic networks of myriad forms are forging new webs of interdependencies among local, regional, national, and macroregional economies in ways that seemingly demand that we mesh both network and territorial understandings of economic development. Well-established trends, such as the huge expansion of production in East Asia and the rise of offshoring in India, are being overlaid with newer dynamics, such as booming agribusiness exports from Brazil, extensive resource-seeking Chinese investments in Africa, and strong growth in domestic demand in China and India, and these are just some of the most visible and well-known manifestations of an incredibly complex series of multiscalar transformations in the global economy.

This much we know. Yet economic geography - a subdiscipline that originates from, and is still overwhelmingly located in, the deindustrializing countries of North America, Western Europe, and Australasia - seems to be struggling to keep up with the pace of contemporary global economic change (cf. Dicken, 2004). To be clear, we are making an argument about emphasis, not omission. As we shall show, there is much ongoing and exciting research in economic geography that is truly coming to grips with transnational economic processes. However, much more progress needs to be made in adjusting both our empirical foci and our theoretical frames, particularly with respect to the developing world and the causes and consequences of the often-rapid and brutal processes of enrollment into the global capitalist economy. Although doing so will not be easy-economic geography is a small subdiscipline that is already arguably spread too thin in thematic and geographic terms - one practical way forward is to continue to knock down what remains of the intellectual-cum-institutional firewall between economic geography and development geography (and, indeed, development studies more generally). There are still further synergies and economies of scale to be derived from removing this entirely artificial distinction (cf. J. Murphy 2008).

An unscientific scan of recent scholarship in economic geography reveals both the problems and possibilities of developing the kind of "global" economic geography that we are espousing. First, although there is an established body of work on the so-called emerging markets - particularly in Eastern and Central Europe and East and Southeast Asia - there are still significant blind spots in the geographic coverage of our research. Latin America, sub-Saharan Africa, and the Middle East, for example, continue to remain largely off the map, yet a strong case can be made that globalizing economic activities have every bit as much effect in these corners of the world, even if other areas seem to reflect better certain forms of economic dynamism. Second, much needs to be done to explore so-called South-South economic connections. There are hot spots of research in this vein, most notably the rich array of work on manufacturing production networks in Asia (e.g., Yeung 2009) but also in other areas-for example, China's increasingly dramatic effects on resource-exporting economies in sub-Saharan Africa or the recent

${ }^{7}$ Christian Berndt, Neil M. Coe, * Jim Glassman, Peter Lindner, Mark Lorenzen, Becky Mansfield, and James T. Murphy. 
investments of Brazilian ethanol producers into the same continent - research is thinner on the ground or nonexistent. Carmody and Owusu (2007), for example, provide a fascinating initial assessment of the reorientation of Africa's geoeconomic relations from "North to East." Here the variegation of the "South" comes more clearly into view.

Third, moreover, these limitations have constrained the degree to which the experiences of certain economic actors (e.g., consumers, workers, and entrepreneurs) are able to speak back to theories that were developed in the home regions of economic geography. Several years ago, Yeung and Lin (2003) alerted us to the potential of "theorizing back" from new areas of economic dynamism with varied political-institutional configurations, to enhance the depth and reach of - or at least appreciate the limits to - existing theoretical frames. Although "theorizing across" may be a better metaphor in the contemporary world system, we concur with Pollard, McEwan, Laurie, and Stenning (2009) that much more still needs to be done in this regard. To be clear, it is not that economic geographers lack the theoretical tools for exploring global economic interconnections - far from it. Avowedly multiscalar and multiactor frameworks, such as the global production network perspective, are striving to grapple with the inherent complexity of the global economy,

122 while others may choose cognate approaches that use the tools of actor-network theory, marketization studies, or transnationalism, for example, to tackle similar issues. Rather, the sectoral and geographic reach of their application needs to be extended, as do attempts to rework and refine frameworks that use the findings from currently unchartered territories.

In sum, we must devote more energy and attention to tracing, unpacking, and interrogating the nature, meaning, and dynamics of marketization processes and transnational production networks as they are manifest within, and in relation to, communities, economies, regions, industries, and environments throughout the global economy. A key common concern is to emphasize the varied ways that actors in an increasingly diverse range of places are being enrolled — and are enrolling themselves — in global markets and transnational production networks of different kinds. For example, Murphy and Schindler (2011) detailed the different rationalities and strategic options of globalizing firms in the Bolivian wood products industry, Ouma (2010) explored how global agrifood standards are interpreted and reworked locally in the Kenyan horticulture sector, and Wells (2009) revealed the continued necessity for local worker autonomy and agency when seeking to improve labor standards in countries like Mexico. Rather than view certain places as "preindustrial" or as existing largely outside the industrial capitalist spaces of the global economy, scholars such as these have focused on the ongoing processes of marketization and labor market restructuring in what Timothy Mitchell (2007) termed the "frontier regions" of the capitalist world. Fully exploring the impacts of these processes will also involve complementing studies of economic upgrading and the strategies of firms with those on social upgrading processes and livelihoods (cf. Bebbington 2003; Stenning Smith, Rochovská, and Świątek 2010).

Thus the promise of marketization and transnational production network approaches lies in their ability to provide more dynamic, inclusive, and multiscalar conceptual frameworks through which we can examine the socioeconomic implications of global capitalism's geographic expansion. By extending these frameworks of research to all regions of the global economy, economic geographers can reveal how the multiscalar power relations between, and the diverse agencies of, socioeconomic actors facilitate or prevent integration into world markets and transnational production networks and explain why market (dis)integration can lead to highly uneven development outcomes at the global and local scale. Moreover, concerted research along these lines will elucidate how and why variegated and polycentric forms of capitalism are emerging and will challenge 
economic geographers to rethink many of the concepts and theories that we use to explain the structure and dynamics of the global space economy.

Of course, production network and marketization theorizations can deliver on this promise only if social groups in all regions are studied carefully and understood as agents who are able to set their own agendas - as with negotiations between African resource exporters and Chinese investors - and potentially to resist the demands of powerful external actors, as when South American governments and social movements collectively challenge the Washington consensus. Thus, economic geographers need to see global markets and production systems as geopolitical as well as geoeconomic formations. Glassman (forthcoming), for example, outlined how wars, transnational trade agreements, and state-to-state negotiations over investment and other forms of more localzed social struggles are powerful shapers of global interconnections. Overall, economic geographers need to explore how actors in all the places that constitute markets and production networks - albeit with different positionalities and resources (cf. Coe and Jordhus-Lier, forthcoming) — are strategically engaging with and transforming the world economy on a daily basis.

\section{Concluding Remark ${ }^{8}$}

The five themes elaborated here reflect attempts to articulate an urgent need of intellectual engagements with various emerging issues, although obviously varied and still evolving conceptual frameworks. Combined, these themes showcase the hallmark strength of our discipline, which is to generate new insights on dominant or emerging logics underlining capitalism(s) and to offer novel interpretations to the processes of territorialization. Each section demonstrates solid engagements with contemporary issues of global concerns, with a liberal use of wide-ranging interdisciplinary literatures. They not only represent ongoing reconceptualizations taking place in the disciplineinvolving new takes on markets, environment, and property - but also suggest a number of potential cross-cutting themes, for example, financialization of the environment and the nature of marketization in South-South trade.

Did we meet our goals in generating ideas that contribute to the future of our discipline in some fashion through the workshop? The value of this editorial is not in its comprehensiveness or in even-handedness; rather, it is a collective, yet highly selective attempt to showcase various frontiers that are to be further engaged and elaborated. On the one hand, our divergent epistemologies and methodologies were ideally suited for sharpening our intellectual pursuits. On the other hand, the diversity of opinion in the groups at times forestalled attempts to push forward certain ideas and themes. In general, we found collective discussions enriching but collective writing a considerable challenge. The latter is a formidable task in any circumstance but especially so when consensus is not a primary objective.

Furthermore, attempts to achieve a forward-looking agenda were balanced against a more cautious approach; our generational experience in enduring multiple "turns" in short successions nurtured a certain degree of aversion to what cynics among us might call "buzzwords." Yet outcomes of the workshop more than remind us of the challenge of shaping the disciplinary future without a dominant discourse, which is an important vehicle of achieving disciplinary unity and accomplishing a degree of intellectual influence. Because of what I suspect to be an implicit recognition of this, each of the five

\footnotetext{
8 Yuko Aoyama.
} 
themes advocates for their need to occupy a central position in the discipline, which is perceived to reside elsewhere. Intellectual competition can have positive outcomes, and in this particular case, we believe it worked productively in our collective attempt to generatethe research agenda.

Our identity as economic geographers remains something of a tacit knowledge only understood by the insiders. One of the recurring challenges is to operationalize spatiality as conceived in a unique, and somewhat lasting, framework epistemologically and methodologically in a manner that solidifies our disciplinary strength. Stopping short of advocating for the return of dominant discourses, the task ahead is to find a better articulation of our commonalities while maintaining porous boundaries for new memberships. The process of exploration is ongoing. At the workshop, a small-group deliberation proved to be far superior in producing strategic outcomes - and the postworkshop survey reflected that fact-whereas the large-group session was frustrating to some, indicating that spelling out our futures - even in multiple tracks and without a search for consensus - remains something of a challenge. Nonetheless, these discussions were useful, and many of us thought that they should be held periodically, even if the themes

124 that emerged from the workshop are still exploratory at this stage.

Our goal is to nurture discussion circles beyond a single event and to position this workshop as a starting point for ongoing reflections, an attempt to break away more systematically from our daily routines and dedicate some time to contemplate our collective disciplinary future. Our intention is to continue to support broad and agenda-shaping discussions in the future, involving different individuals for different occasions.

Alley, R. B., Marotzke, J., Nordhaus, W. D., Overpeck, J. T., Peteet, D. M., Pielke., R. A., Pierrehumbert, R. T., Rhines, P. B., Stocker, T. F., Talley, L. D., and Wallace, J. M. 2005. Abrupt climate change. Science 299:2005-10.

Bebbington, A. 2003. Global networks and local developments: Agendas for development geography. Tijdschrift voor Economische en Sociale Geografie 94:297-309.

Boltanski, L., and Thévenot, L. 2006. On justification: Economies of worth. Princeton, N.J.: Princeton University Press.

Bridge, G. 2008. Environmental economic geography:A sympathetic critique. Geoforum 39:76-8I.

Bumpus, A., and Liverman, D. 2008. Accumulation by decarbonization and the governance of carbon offsets. Economic Geography 84:I27-55.

Caliskan, K., and Callon, M. 20I0. Economization, part 2: A research programme for the study of markets. Economy and Society 39:I-32.

Carmody, P. R., and Owusu, F.Y. 2007. Competing hegemons? Chinese versus American geo-economic strategies in Africa. Political Geography 26:504-24.

Castree, N., and Braun, B. 200I. Social nature: Theory, practice, and politics. Malden, Mass.: Blackwell.

Coe, N. M., and Jordhus-Lier, D. Forthcoming. Constrained agency? Re-evaluating the geographies of labour. Progress in Human Geography.

Costanza R.; Cumberland J. H.; Daly, H.; Goodland, R.; and Norgaard, R. B. 1997. An introduction to ecological economics. Boca Raton, Fla.: St. Lucie Press.

Dicken, P. 2004 Geographers and "globalization": (Yet) another missed boat? Transactions of the Institute of British Geographers 29(I):5-26. 
Ellis, E. C., and Ramankutty, N. 2008. Putting people in the map: Anthropogenic biomes of the world. Frontiers in Ecology and the Environment 6:439-47.

Emirbayer, M. 1997. Manifesto for a relational sociology. American Journal of Sociology 103:28I317.

Gibbs, D. 2006. Prospects for an environmental economic geography: Linking ecological modernization and regulationist approaches. Economic Geography 82:193-215.

Glassman, J. Forthcoming. The geo-political economy of global production networks. Geography Compass.

Grabher, G. 2006. Trading routes, bypasses, and risky intersections: Mapping the travels of "networks" between economic sociology and economic geography. Progress in Human Geography 30:163-89.

Hayter, R. 2008. Environmental economic geography. Geography Compass 2-3:83I-50.

Johnston, R. 2002. Reflections on Nigel Thrift's optimism: Political strategies to implement his vision. Geoforum 33:42I-5.

-2006. The politics of changing human geography's agenda:Textbooks and the representation of increasing diversity. Transactions of the Institute of British Geographers 31:286-303.

Knorr Cetina, K. 2006. The market. Theory Culture and Society 23(2-3):55 I-6.

Knox-Hayes, J. 2009. The developing carbon financial service industry: Expertise, adaptation and complementarity in London and New York. Journal of Economic Geography 9:749-77.

Leichenko, R., and O'Brien, K. 2008. Environmental change and globalization: Double exposures. New York: Oxford University Press.

Martin, R. 200I. Geography and public policy:The case of the missing agenda. Progress in Human Geography 25:189-210.

Mitchell, T. 2002. Rule of experts: Egypt, techno-politics, modernity. Berkeley: University of California Press

-2007. The properties of markets. Do economists make markets? ed. D. MacKenzie, F. Muniesaand, and L. Siu, 244-75. Princeton, N.J., Princeton University Press.

Murphy, J. 2008. Economic geographies of the Global South: Missed opportunities and promising intersections with development studies. Geography Compass 2:85I-73.

Murphy, J.T., and Schindler, S. 20II. Globalizing development in Bolivia? Alternative networks and value-capture challenges in the wood products industry. Journal of Economic Geography II:6I-85.

Murphy, M. 2008. Chemical regimes of living. Environmental History 13:695-703.

Nordhaus, W. D. 2006. Geography and macroeconomics: New data and new findings. Proceedings of the National Academy of Sciences 103(10):3510-17.

2010 . Economic aspects of global warming in a post-Copenhagen environment. Proceedings of the National Academy of Sciences 107(26): I 172I-26.

Ostrom, E. 2009. A general framework for analyzing sustainability of social-ecological systems. Science 325:419-22.

Ouma, S. 2010. Global standards, local realities: Private agrifood governance and the restructuring of the Kenyan horticulture industry. Economic Geography 86: 197-222.

Pachucki, M. A., and Breiger, R. L. 2010. Cultural holes: Beyond relationality in social networks and culture. Annual Review of Sociology 36:205-24.

Peck, J., and Olds, K. 2007. The Summer Institute in Economic Geography. Economic Geography 83:309-18.

Pollard, J. S.; McEwan, C.; Laurie, N. D.; and Stenning, A. C. 2009. Economic geography under postcolonial scrutiny. Transactions of the Institute of British Geographers 34:I37-42. 
Soyez, D., and Schulz, C. 2008. Facets of an emerging environmental economic geography (EEG). Geoforum 39:17-19.

Stark, D. 2009. The sense of dissonance: Accounts of worth in economic life. Princeton, N.J.: Princeton University Press.

Stenning, A.; Smith, A.; Rochovská, A.; and Świątek, D. 20I0. Domesticating neo-liberalism: Spaces of economic practice and social reproduction in post-socialist cities. Oxford, U.K.: Blackwell.

Stiglitz, J. E.; Sen, A.; and Fitoussi, J.-P. 2009. Report by the Commission on the Measurement of Economic Performance and Social Progress.

Thrift, N. 2002. The future of geography. Geoforum 33:291-98.

Turner II, B. L.; Lambin, E.; and Reenberg, A. 2007. The emergence of land change science for global environmental change and sustainability. Proceedings of the National Academy of Sciences 104(52):20666-7I.

Wells, D. 2009. Local worker struggles in the Global South: Reconsidering northern impacts on international labour standards. Third World Quarterly 30:567-79.

Wuchty, S.; Jones, B. F.; and Uzzi, B. 2007. The increasing dominance of teams in production of knowledge. Science 316:1036-39.

Yeung, H.W-C. 2009. Regional development and the competitive dynamics of global production networks: An East Asian perspective. Regional Studies 43:325-5I.

Yeung, H. W-C., and Lin, G. C. S. 2003. Theorizing economic geographies of Asia. Economic Geography 79:107-28. 